\title{
AGRO-ECONOMIC PRODUCTIVITY OF RICE- RABI CROP- RICE SYSTEMS IN NORTHWESTERN DROUGHT-PRONE AREAS OF BANGLADESH
}

\author{
M.M. Rahman* \\ Department of Agronomy, Bangladesh Agricultural University, Mymensingh
}

\begin{abstract}
Productivity and economics of different rabi crop-based systems were evaluated at farmers' field in Durgapur upazilla of Rajshahi district, Bangladesh to select the best rabi crop(s) for fitting in the T. Aman rice rabi crop - DDS Aus rice pattern. Nine rabi crops namely, (1) Mustard, (2) Potato, (3) Lentil, (4) Field pea, (5) Radish, (6) Cabbage, (7) French bean, (8) Carrot and (9) Tomato were cultivated during the rabi season in between the two rice crops to form nine cropping patterns. The experiment used Randomized Complete Block Design (RCBD) with three replications. Aman rice variety BRRI dhan57 was transplanted on 12 July 2017 and harvested on 28 October 2017, while, Aus rice variety BRRI dhan28 was sown in the dry cultivated land on 16 March 2018 and harvested on 24 June 2018 while rabi crops were sown/transplanted on 28 November 2017. Proper agronomic management practices were adopted for all the crops in the patterns. Data on yield and related attributes of DDS Aus rice were recorded at harvest. In addition, the yield of Aman rice and all the rabi crops were recorded. In addition, rice equivalent yield of each rabi crop, system yield (total yield of all the crops in the sequence), cost of production, gross return and benefit cost ratios (BCR) of all the patterns were recorded. Results revealed that yield of dry direct seeded Aus rice cv. BRRI dhan28 did not differ significantly due to different rabi crops grown under the respective patterns. The system yield was the highest in T. Aman rice -tomato - DDS Aus rice pattern $\left(19.62 \mathrm{t} \mathrm{ha}^{-1}\right)$ and the lowest with T. Aman rice -mustard - Aus rice pattern (14.63 $\left.\mathrm{t} \mathrm{ha}^{-1}\right)$. Since the market price of a rabi crop changes from year to year, the net profit of a pattern depends on the yield of a crop grown in rabi season. Therefore, any of the nine rabi crops under the trial can be successfully cultivated in between the two rice crops under Aman rice - rabi crop -Aus rice patterns. However, the present study concludes that any of the nine rabi crops can be grown in between the two rice crops but carrot, French bean, mustard, field pea, and tomato could be the most profitable ones for the T. Aman rice - rabi crops -DDS Aus rice patterns.
\end{abstract}

\footnotetext{
* Corresponding Author: rahmanag63@gmail.com
} 
Keywords: Dry direct seeding, Cropping pattern, Rice equivalent yield, System yield

\section{INTRODUCTION}

The cropping patterns of Bangladesh are predominantly rice based. Rice is the staple food and the main element of food security in Bangladesh. About $77.07 \%$ cropped area of Bangladesh is used for rice production, with the annual production of 37.36 million tons from 11.68 million ha of land (AIS, 2020). The rice production in the country has been increased by 3.4 folds over the last four decades. In Bangladesh, more than 55.0 million tons of rice will be required by the year 2050 when population of Bangladesh will be 233.3 million (Basak et al., 2009). The possibility of expanding the area under rice in the near future is limited. Therefore, this extra rice production should to come from the productivity gain.

Rice is mostly cultivated by transplanting of seedling in the puddled soil. Usually, irrigation is not required in Aman season because it coincides with rainy season (June - October). On the other hand, Boro rice requires full irrigation water $(1400 \mathrm{~mm})$ mainly supplied from underground source as the rainfall is scanty during this season (January - May). For irrigation a huge amount of water is lifted from the ground which leads to decline of the water table and causes serious environmental hazards. In practice, Boro rice uses about $70 \%$ of the total water used in agriculture (Rahman, 2018). At present the water scarcity from both surface and ground sources are looming and under this situation, Boro rice cultivation cannot be sustained. Realizing the fact, the government is discouraging cultivation of Boro rice and encouraging cultivation of Aus or late season Boro rice in the northwestern drought-prone region of Bangladesh. This practice saves substantial amount of irrigation water as it does not require irrigation during the whole crop period rather it requires water for land preparation, crop establishment and also during the early growth stage of the crop. Generally, no irrigation is required during the later stages as this period coincides with rainfall. The harvest of rabi crops depends on their life duration and generally extends from late January to late February. Thus, adoption of late season Boro rice or Aus rice instead of the regularly cultivated Boro rice will allow farmers to grow a rabi crop during the fallow period between Aman rice and Boro/Aus rice (Rahman, 2019).

T. Aman rice - Fallow - T. Boro rice is the major cropping pattern in Bangladesh. Recently, many farmers cultivate mustard, potato and other short duration rabi crops during the rabi season in between the two rice crops. The area under T. Aman riceMustard -T. Boro rice pattern and T. Aman rice - Mustard -T. Bororice pattern is increasing. Under these patterns, Boro rice is transplanted during February and even in March. Thus, the second rice crop is mainly cultivated in late Boro/Aus season. The late Boro/Aus rice still requires huge amount of irrigation for the puddling, crop establishment and vegetative stages. This irrigation water use can be cut 
substantially if the crop is grown under dry direct seeded system instead of the conventional puddle transplanted system. The dry direct seeded (DDS) rice system is an alternative approach which reduces irrigation requirement by more than $50 \%$ compared with in the puddle transplanted method of rice cultivation (Rahman, 2019). Thus, the replacement of transplanting method with dry direct seeding method in Boro/Aus rice season could contribute to the saving of huge irrigation water. The adoption of T. Aman rice - Rabi crops - DDS Boro/Aus rice pattern instead of T. Aman rice - Fallow - T. Boro/Aus rice pattern will allow cultivation of many rabi crops in the fallow lands during rabi season before late Boro/Aus cultivation. This would help in increasing cropping intensity, crop diversity and farm income. Such an intensification and diversification of cropping systems may allow improving the productivity and sustainability of agricultural production. The present study has been undertaken with a view to evaluate the agro-economic productivity of various T. Aman Rice - Rabi crops - DDS Aus rice patterns.

\section{MATERIALS AND METHODS}

\section{Site and soil}

The experiment was conducted at farmers' field in Khitrokashipur village of Durgapur upazilla in Rajshahi district. The field is located at $24^{\circ} 75^{\prime} \mathrm{N}$ latitude, $90^{\circ} 50^{\prime} \mathrm{E}$ longitude and at an altitude of $18 \mathrm{~m}$. The area falls under High Barind Tract agro-ecological zone (AEZ-26) having Non-calcareous dark grey floodplain soil. The land was a medium high with moderate drainage facilities. The soil was silt loam having $\mathrm{pH}$ value of 6.5. The particle density and bulk density values of soil were 2.60 and $1.35 \mathrm{~g} \mathrm{cc}^{-1}$, respectively. Soil contained $1.78 \%$ organic matter, $0.14 \%$ total $\mathrm{N}$, $1.98 \mu \mathrm{g}^{-1}$ available $\mathrm{P}, 0.10 \mathrm{meq} 100 \mathrm{~g}^{-1}$ exchangeable $\mathrm{K}$ and $4.56 \mu \mathrm{g} \mathrm{g}^{-1}$ available $\mathrm{S}$. The experimental area falls under the sub-tropical climate characterized by its heavy rainfall during Kharif season (April to September) and scanty rainfall during Rabi season (October to March).

\section{Experimental Treatments and Design}

Nine rabi crops were included in the trial in between transplanted Aman rice cv. BRRI dhan57 and dry direct seeded (DDS) Aus rice cv. BRRI dhan28 to form nine cropping patterns. The rabi crops included were: (1) Mustard, (2) Potato, (3) Lentil, (4) Field pea, (5) Radish, (6) Cabbage, (7) French bean, (8) Carrot and (9) Tomato. Therefore, the cropping patterns tested were: (1) Aman rice - Mustard - DDS Aus rice, (2) Aman rice - Potato - DDS Aus rice, (3) Aman rice - Lentil - DDS Aus rice, (4) Aman rice - Field pea - DDS Aus rice, (5) Aman rice - Radish - DDS Aus rice, (6) Aman rice - Cabbage - DDS Aus rice, (7) Aman rice - French bean - DDS Aus rice, (8) Aman rice - Carrot - DDS Aus rice and (9) Aman rice - Tomato - DDS Aus rice. The experiment used a RCB design with three replications. The unit plot size was $4.0 \mathrm{~m} \times 2.5 \mathrm{~m}$. 


\section{Crop management}

Aman rice variety BRRI dhan57 was cultivated by transplanting of 25 day old seedlings at $25 \mathrm{~cm} \times 15 \mathrm{~cm}$ allocating 3-4 seedlings hill ${ }^{-1}$ on 10 July 2017 . The crop was harvested at maturity on 27 October 2017 and the yield was recorded from randomly selected five spots of $10 \times 10 \mathrm{~m}^{2}$ area of the rice fields. The rabi crops were sown/transplanted on 28 November 2017 maintaining their recommended spacings and after harvest of the rabi crops, Aus rice cv. BRRI dhan 28 was sown on 16 March 2018 by hand at $25 \mathrm{~cm} \times 15 \mathrm{~cm}$ spacing allocating 3-4 seeds hill ${ }^{-1}$. The land was fertilized as per nutrient recommendation for each crop stated in the Fertilizer Recommendation Guide-2018 (BARC, 2018) in the form of urea, triple super phosphate, muriate of potash, gypsum and zinc sulphate (Table 1). All the agronomic managements were done as and when needed following the standard protocol. The dry direct seeded rice was harvested on 24 June 2018.

Table 1. Nutrient recommendation $\left(\mathrm{kg} \mathrm{ha}^{-1}\right)$ for different crops under the trial (BARC, 2018)

\begin{tabular}{llllll}
\hline Crop & $\mathrm{N}$ & $\mathrm{P}$ & $\mathrm{K}$ & $\mathrm{S}$ & $\mathrm{Zn}$ \\
\hline Mustard & 90 & 27 & 32 & 10 & 1.0 \\
Potato & 135 & 30 & 90 & 10 & 2.0 \\
Lentil & 18 & 24 & 30 & 18 & 2.0 \\
Field pea & 24 & 48 & 30 & 9 & 1.2 \\
Radish & 125 & 40 & 90 & 20 & 2.0 \\
Cabbage & 180 & 66 & 50 & 16 & 1,5 \\
French bean & 92 & 96 & 75 & 25 & 1.2 \\
Carrot & 120 & 35 & 80 & 20 & 1.0 \\
Tomato & 135 & 45 & 50 & 10 & 1.0 \\
Aman rice (cv. BRRI dhan57) & 90 & 10 & 30 & 8 & 1.0 \\
Aus rice (cv. BRRI dhan28) & 75 & 10 & 25 & 6 & 0.6 \\
\hline
\end{tabular}

\section{Data recording}

Data on yield and related attributes of Aus rice were recorded. The yield of rabi crops and the rice equivalent yield of each rabi crop was also recorded. Data on economic parameters of different cropping patterns such as (i) System yield (yield of all the crops in a pattern), (ii) Cost of production, (iii) Gross return and (iv)Benefit cost ratio (BCR) were also recorded.

Rice equivalent yield (REY) was calculated to compare system performance by converting the yield of each rabi crop into equivalent Boro rice yield on a price basis, using the formula: 
REY (of crop $\mathrm{x})=\mathrm{Y}_{\mathrm{x}} \times\left(\mathrm{P}_{\mathrm{x}} / \mathrm{P}_{\mathrm{r}}\right)$

Where, $Y_{x}=$ yield of crop $x$ (tons harvest product ha ${ }^{-1}$ ), $P_{x}=$ price of cropx, and $\mathrm{P}_{\mathrm{r}}=$ price of rice.

Net return or profit was calculated by subtracting production cost from the gross value of the produce, including by-product value or gross return. Prices used for harvest products were average prices observed during the experimental period. The benefit: cost ratio (BCR) was calculated by dividing the net return by the production cost for individual crops and for various systems.

\section{Data analysis}

Data on yield and related parameters of dry direct seeded rice were subjected to statistical analysis using analysis of variance technique and mean comparison was done using STATISTIX 10 computer software.

\section{RESULTS AND DISCUSSION}

\section{Yield performance of Boro rice}

Grain yield of dry direct seeded (DDS) Aus rice cv. BRRI dhan28 did not differ significantly due to the preceding rabi crops grown under nine T. Aman rice $-r a b i$ crop - DDS Aus rice cropping pattern. The grain yield ranged between $5.45 \mathrm{t} \mathrm{ha}^{-1}$ and $6.29 \mathrm{t} \mathrm{ha}^{-1}$ (Table 3). The straw yield of DDS Aus rice did not also differ significantly due to preceding rabi crops in the patterns. Plant height, total tiller hill ${ }^{-1}$, effective tiller hill ${ }^{-1}$, non-effective tillers hill ${ }^{-1}$ and number of grains panicle ${ }^{-1}$ of DDS Aus rice differed significantly due to the preceding rabi crops in the pattern (Table 2).

On the other hand, sterile spikelet panicle ${ }^{-1}$ and thousand grain weight of DDS Aus rice did not differ significantly due to different T. Aman rice - rabi crop - DDS Aus rice cropping pattern (Table 3). The tallest plants of DDS Boro rice $(113 \mathrm{~cm})$ were found in T. Aman rice - Tomato - DDS Aus rice pattern which was statistically similar with T. Aman rice - French bean - DDS Aus rice pattern. The highest numbers of total and effective tiller hill ${ }^{-1}$ were found with patterns having French bean and Tomato and the lowest with lentil and Cabbage. The highest number of non-effective tiller (2.67) was found in Aman rice - mustard- DDS Aus rice pattern and the lowest number (0.42) was noted in Aman rice -tomato- DDS Aus rice pattern. The highest number of grains panicle ${ }^{-1}$ of DDS Aus rice was found in Aman rice carrot- DDS Aus rice pattern which was closely followed by Aman rice -tomato DDS Boro pattern and Aman rice -lentil- DDS Aus rice pattern while the lowest was found in Aman rice -French bean - DDS Aus rice pattern (Table 3). 
Table 2. Effect of different T. Aman rice - rabi crops - DDS Aus rice cropping pattern on plant height and tiller density of dry direct seeded Aus rice cv. BRRI dhan 28

\begin{tabular}{lllll}
\hline $\begin{array}{c}\text { Cropping } \\
\text { pattern }\end{array}$ & $\begin{array}{c}\text { Plant height } \\
(\mathrm{cm})\end{array}$ & $\begin{array}{c}\text { Total tillers } \\
\text { hill }^{-1}(\text { no. })\end{array}$ & $\begin{array}{c}\text { Effective tillers } \\
\text { hill }^{-1}(\text { no. })\end{array}$ & $\begin{array}{c}\text { Non effective tillers } \\
\text { hill }^{-1}(\text { no. })\end{array}$ \\
\hline Pattern 1 & $106.7 \mathrm{~cd}$ & $17.33 \mathrm{abc}$ & $14.67 \mathrm{abc}$ & $2.66 \mathrm{a}$ \\
Pattern 2 & $107.0 \mathrm{~cd}$ & $16.50 \mathrm{abc}$ & $15.50 \mathrm{abc}$ & $1.08 \mathrm{~cd}$ \\
Pattern 3 & $108.2 \mathrm{bcd}$ & $14.17 \mathrm{c}$ & $13.42 \mathrm{c}$ & $0.75 \mathrm{~cd}$ \\
Pattern 4 & $107.2 \mathrm{~cd}$ & $14.83 \mathrm{bc}$ & $13.58 \mathrm{bc}$ & $1.25 \mathrm{~cd}$ \\
Pattern 5 & $109.0 \mathrm{bc}$ & $15.58 \mathrm{abc}$ & $14.66 \mathrm{abc}$ & $0.92 \mathrm{~cd}$ \\
Pattern 6 & $108.6 \mathrm{bc}$ & $13.92 \mathrm{c}$ & $13.17 \mathrm{c}$ & $0.75 \mathrm{~cd}$ \\
Pattern 7 & $111.3 \mathrm{ab}$ & $19.17 \mathrm{a}$ & $16.83 \mathrm{a}$ & $2.33 \mathrm{ab}$ \\
Pattern 8 & $105.0 \mathrm{~d}$ & $16.50 \mathrm{abc}$ & $16.08 \mathrm{ab}$ & $0.42 \mathrm{~d}$ \\
Pattern 9 & $113.0 \mathrm{a}$ & $18.25 \mathrm{ab}$ & $16.75 \mathrm{a}$ & $1.50 \mathrm{bc}$ \\
Level of sign. & $* *$ & $*$ & $*$ & $* *$ \\
LSD & 3.49 & 4.66 & 2.63 & 0.98 \\
\hline
\end{tabular}

In a column, figures with same letter or without letter do not differ significantly, whereas figures with dissimilar letter differ significantly; *= Significant at $5 \%$ level of probability;

$* *=$ Significant at $1 \%$ level of probability; $* * *=$ Significant at $0.01 \%$ level of probability; ns $=$ non significance

[Patterns: (1). Aman rice - Mustard - DDS Aus rice, (2). Aman rice - Potato - DDS Aus rice, (3). Aman rice - Lentil - DDS Aus rice, (4). Aman rice - Field pea - DDS Aus rice, (5). Aman rice - Radish - DDS Aus rice, (6). Aman rice - Cabbage - DDS Aus rice, (7). Aman rice - French bean - DDS Aus rice, (8). Aman rice - Carrot - DDS Aus rice and (9). Aman rice - Tomato. - DDS Aus rice]

The present study showed that the yield of DDS Aus rice (the second rice crop in the pattern) did not vary much due to inclusion of different rabi crops in different $\mathrm{T}$. Aman rice - rabi crops - DDS Aus rice patterns due to change of the rabi crops. Rajon (2019) conducted a similar experiment at Mymensingh and found that the DDS Boro rice yield did not differ due to different rabi crops grown in T. Aman rice - rabi crops - DDS Boro rice patterns. On the other hand, Singh and Beniwal (1983) reported yield decline of rice after mustard/rapeseed while Biswas and Mitra (1987) found rice yield increased after potato. Mustard is a nutrient exhaustive crop which might have contributed to the reduced yield of the succeeding rice crop while potato contributed to nutrient building up that attributed to increased yield of the succeeding rice crop. Biswas (2015) reported that organic matter increased considerably after jute and potato, irrespective of cropping systems. This might be due to greater rhizo- 
deposition and leaf shedding of jute throughout its growth period and due to the incorporation of potato haulm at harvest, both contributing to an increase in organic carbon.

Table 3. Effect of different T. Aman rice - rabi crops - DDS Aus rice cropping pattern on yield and related attributes of dry direct seeded Aus rice cv. BRRI dhan 28

\begin{tabular}{lccccc}
\hline Rabi crops & $\begin{array}{c}\text { Grains } \\
\text { panicle } \\
\text { (no.) }\end{array}$ & $\begin{array}{c}\text { Sterile spikelet } \\
\text { panicle }^{-1}(\text { no. })\end{array}$ & $\begin{array}{c}\text { Weight of } \\
1000 \text { grains } \\
(\mathrm{g})\end{array}$ & $\begin{array}{c}\text { Grain yield } \\
\left(\mathrm{t} \mathrm{ha}^{-1}\right)\end{array}$ & $\begin{array}{c}\text { Straw yield } \\
\left(\mathrm{t} \mathrm{ha}^{-1}\right)\end{array}$ \\
\hline Pattern 1 & $84.00 \mathrm{bc}$ & 20.67 & 21.41 & 5.63 & 6.19 \\
Pattern 2 & $84.20 \mathrm{bc}$ & 23.13 & 21.28 & 6.30 & 6.34 \\
Pattern 3 & $87.77 \mathrm{ab}$ & 24.67 & 21.46 & 5.46 & 5.88 \\
Pattern 4 & $81.63 \mathrm{bc}$ & 21.30 & 21.12 & 5.74 & 6.09 \\
Pattern 5 & $75.50 \mathrm{bc}$ & 20.67 & 21.01 & 5.45 & 5.78 \\
Pattern 6 & $74.53 \mathrm{c}$ & 20.83 & 20.74 & 5.48 & 5.63 \\
Pattern 7 & $76.43 \mathrm{bc}$ & 22.27 & 21.07 & 5.76 & 5.91 \\
Pattern 8 & $97.77 \mathrm{a}$ & 21.79 & 21.49 & 6.01 & 6.07 \\
Pattern 9 & $87.83 \mathrm{ab}$ & 19.97 & 21.28 & 6.12 & 6.02 \\
Level of sign. & $*$ & $\mathrm{~ns}$ & $\mathrm{~ns}$ & $\mathrm{~ns}$ & $\mathrm{~ns}$ \\
LSD & 12.75 & 7.35 & 0.71 & 1.06 & 0.69 \\
\hline
\end{tabular}

[Patterns: (1). Aman rice - Mustard - DDS Aus rice, (2). Aman rice - Potato - DDS Aus rice, (3). Aman rice - Lentil - DDS Aus rice, (4). Aman rice - Field pea - DDS Aus rice, (5). Aman rice - Radish - DDS Aus rice, (6). Aman rice - Cabbage - DDS Aus rice, (7). Aman rice - French bean - DDS Aus rice, (8). Aman rice - Carrot - DDS Aus rice and (9). Aman rice - Tomato. - DDS Aus rice]

\section{Agro-economic productivity}

Nine rabi crops such as mustard, potato, lentil, field pea, radish, cabbage, French bean, carrot and tomato were included in the T. Aman rice - rabi crop - DDS Aus rice pattern to form nine cropping patterns (Table 4). The rice equivalent yield (REY) of different rabi crops were calculated based on their market price. It was found that the REY was the highest $\left(7.50 \mathrm{t} \mathrm{ha}^{-1}\right)$ for potato and lowest $\left(3.83 \mathrm{t} \mathrm{ha}^{-1}\right)$ for radish. Further, the system yield for each pattern was calculated by adding the yield of Aman rice, REY and DDS Aus rice yield. The highest system yield was found in T. Aman rice - Potato - DDS Aus rice pattern $\left(18.30 \mathrm{t} \mathrm{ha}^{-1}\right)$ and the lowest with T. Aman rice Radish - DDS Boro rice pattern (13.78 $\left.\mathrm{t} \mathrm{ha}^{-1}\right)$. The gross cost of production for the crops under each pattern was calculated and the highest cost was noticed in T. Aman rice - Potato - DDS Aus rice pattern (BDT 279150.00) while the lowest in T. Aman 
rice - Carrot - DDS Aus rice pattern (BDT 165300.00). The benefit cost ratio (BCR) was the highest in T. Aman rice - Carrot - DDS Aus rice pattern (1.99) and the lowest (1.06) in T. Aman rice - Radish - DDS Aus rice pattern (Table 4).

Table 4. System productivity and benefit cost ratio (BCR) of different T. Aman rice - rabi crop - DDS Aus rice cropping patterns

\begin{tabular}{clccccc}
\hline Rabi crops & $\begin{array}{c}\text { Rabi crop } \\
\text { yield } \\
\left(\mathrm{t} \mathrm{ha}^{-1}\right)\end{array}$ & $\begin{array}{c}\text { REY of the } \\
\text { rabi crop } \\
\left(\mathrm{t} \mathrm{ha}^{-1}\right)\end{array}$ & $\begin{array}{c}\text { DDS Boro } \\
\text { rice yield } \\
\left(\mathrm{t} \mathrm{ha}^{-1}\right)\end{array}$ & $\begin{array}{c}\text { System } \\
\text { yield } \\
\left(\mathrm{t} \mathrm{ha}^{-1}\right)\end{array}$ & $\begin{array}{c}\text { System cost } \\
(\mathrm{BDT})\end{array}$ & $\begin{array}{c}\text { BCR of } \\
\text { the } \\
\text { pattern }\end{array}$ \\
\hline Pattern 1 & 1.80 & 4.50 & 5.63 & 14.63 & 174000 & 1.68 \\
Pattern 2 & 15.00 & 7.50 & 6.30 & 18.30 & 279150 & 1.31 \\
Pattern 3 & 1.20 & 5.10 & 5.46 & 15.06 & 183600 & 1.64 \\
Pattern 4 & 1.45 & 3.98 & 5.74 & 14.22 & 172100 & 1.65 \\
Pattern 5 & 17.0 & 3.83 & 5.45 & 13.78 & 260000 & 1.06 \\
Pattern 6 & 17.0 & 5.10 & 5.48 & 15.08 & 262700 & 1.15 \\
Pattern 7 & 1.50 & 5.25 & 5.76 & 15.51 & 175600 & 1.77 \\
Pattern 8 & 18.0 & 6.00 & 6.01 & 16.51 & 165300 & 1.99 \\
Pattern 9 & 18.0 & 6.12 & 6.12 & 16.74 & 218300 & 1.53 \\
\hline
\end{tabular}

Yield of $\mathrm{T}$. Aman rice $=4.50 \mathrm{t} \mathrm{ha}^{-1}$, REY $=$ yield of the rabi crop converted to the yield of Aus rice. [ $\{$ Price of crops $(\mathrm{BDT} / \mathrm{kg})$ : mustard $=50$, potato $=10$, lentil $=85$, field pea $=55$, radish $=4.5$, cabbage $=$ 8.50 , French bean $=70$, carrot $=8$, Aman rice $=22$, and Aus rice $=20\}$. The cost of production $(\mathrm{BDT} / \mathrm{ha})$ for Aman rice $=48625$ and Aus rice $=61075]$

[Patterns : (1). Aman rice - Mustard - DDS Aus rice, (2). Aman rice - Potato - DDS Aus rice, (3). Aman rice - Lentil - DDS Aus rice, (4). Aman rice - Field pea - DDS Aus rice, (5). Aman rice - Radish - DDS Aus rice, (6). Aman rice - Cabbage - DDS Aus rice, (7). Aman rice - French bean - DDS Aus rice, (8). Aman rice - Carrot - DDS Aus rice and (9). Aman rice - Tomato. - DDS Aus rice]

In an experiment at Mymensingh, Rajon (2019) reported the highest REY with Cabbage and the lowest with Garden pea. On the other hand, Rahman (2018) found the highest REY with mustard and lowest with Cabbage in Mymensingh site, while the highest REY was found with potato and lowest with Mustard at Rajshahi site. Rahman (2018) also reported that the highest system yield was recorded with $\mathrm{T}$. Aman rice - Potato - DDS Aus rice pattern while the lowest was recorded with T. Aman rice - Mustard - DDS Aus rice in Mymensingh. In Rajshahi, the highest system yield was recorded in T. Aman rice - Carrot - DDS Boro rice and the lowest with T. Aman rice - Cabbage - DDS Boro rice. Thus, it was apparent from the study that REY and SY are the two good indicators of economic productivity of a pattern may be subjected to abrupt change mainly due to the flexibility of the market price of the product. Since the price is variable with time and space dimension the profit depends on the demand of the crop for a geographic location although the yield of the 
crops remained unchanged. Due to introduction of high-yielding short duration rice in the 1970s and increasing irrigated area, Boro rice replaced most pulses and rabi crops in this area. Crop intensification and/or diversification has now further increased with inclusion of short duration rapeseed and potato in between Aman rice and $A u s$ rice, resulting in higher production per unit area per unit time, higher nutrient removal, and varying changes in soil fertility as compared with rice-rice (R$\mathrm{R})$ and rice-wheat (R-W) systems (Biswas, 2015). However, it is evident from the present experiment that a number of rabi crops can be grown in between the two rice crops which could surely help increase the farm production and farmers' income. The system yield is the highest with T. Aman rice - Potato- DDS Aus rice pattern but the production cost was also the highest (279150 BDT) inthis pattern. Due to increased production cost the BCR (1.31) of this pattern also T. Aman rice - Potato- DDS Aus rice pattern. The cost of production was the highest for potato which was closely followed by cabbage, carrot and tomato that contributed to the lowering the BCR of these pattern. Biswas (2015) reported that cropping pattern containing potato had the highest levels of yield, net return and benefit to cost ratio. However, in the present study the highest benefit cost ratio was found with T. Aman rice-Carrot - DDS Aus rice pattern which was closelyfollowed by T. Aman rice - French bean - DDS Aus rice pattern, T. Aman rice - Mustard - DDS Aus rice pattern, T. Aman rice - Field pea - DDS Aus rice pattern and T. Aman rice - Lentil - DDS Aus rice pattern.

\section{CONCLUSION}

Farmers of the experimental area generally follow T. Aman rice - Fallow - T. Boro rice patterns. The conventional practice is less productive and highly irrigation water intensive. The present study showed that the cultivation of any rabi crop in between the two rice crops do not have any adverse effect on the yield and productivity of the succeeding dry direct seeded Aus rice. It is also evident that any rabi crops such as potato, tomato, carrot, field pea, french bean, mustard and lentil can be easily grown in between the two rice crops. Nevertheless, the present study concludes that any of the nine rabi crops can be grown in between the two rice crops, however carrot, French bean, mustard, field pea, and tomato could be the most profitable for the $\mathrm{T}$. Aman rice - rabi crops - Aus rice patterns.

\section{ACKNOWLEDGEMENT}

The author is highly grateful to the Project Implementation Unit of Bangladesh Agricultural Research Council (BARC), Farmgate, Dhaka-1215 for funding under the Competitive Research Grant (CRG) sub-project \# 777 under NATP2. 


\section{REFERENCES}

AIS. (2020). Agricultural Diary, Agricultural Information Service, Khamar Bari, Dhaka1215.

BARC. (2018). Fertilizer Recommendation Guide-2018. Bangladesh Agriculture Research Council (BARC). Farmgate, New Airport Road, Dhaka.

Basak, J.K., Ali, M.A., Islam, M.N. and Alam, M.J.B. (2009). Assessment of the effect of climate change on Boro rice production in Bangladesh using CERES-Rice model, Proceedings of the International Conference on Climate Change Impacts and Adaptation Strategies for Bangladesh. Pp. 103-113.

Biswas, B. (2015). Cropping System: Research Approach. LAP LAMBERT Academic Publishing. Germany.

Biswas, G.C. and Mitra, P.C. (1987). Residual effect of fertilizers applied to potato and rice on the yield of jute fibre in rice-potato-jute cropping sequence. Jute Development Journal, 7(1): 43-53.

Chatterjee, B.N., Banerjee, N.C., Ghosh, D.C. and Debnath, P.K. (1978). Response to P, K and FYM in multiple cropping with potato. Journal of the Indian Potato Association, 5: 9-12.

Ghosh, D.C. and Malik, G.C. (1999). Fertility management in potato under potato- sesamerice cropping system. Environmental Ecology, 17: 643-645.

Rahman, M.M. (2018). Dry direct seeded Boro rice-based cropping patterns for producing more with less water. Department of Agronomy, Bangladesh Agricultural University, Mymensingh. Pp. 1-28.

Rahman, M.M. (2019). Potential benefits of dry direct seeded rice culture: A review. Fundamental and Applied Agriculture, 4(2): 1-15.

Rajon, M.K. (2019). Effect of rabi crops on agroeconomic performance of different T. Aman - Rabi - Dry direct seeded Boro cropping systems. MS Thesis. Department of Agronomy, Bangladesh Agricultural University, Mymensingh. Pp. 22-32.

Singh, G.B. and Beniwal, R.K. (1983). Performance of wheat and mustard in cropping sequences in Sikkim. Indian Journal of Agriculture Science, 53:820-25. 